\title{
The Effects of Rhizobium, Mycorrhizal Inoculations and Diammonium Phosphate (DAP) on Nodulation, Growth, and Yield of Soybean
}

\author{
Salih S. H*, S.A.M. Hamd, Y. M. I. Dagash. \\ Sudan University of Science and Technology (SUST), Sudan
}

Copyright (C) 2015 Horizon Research Publishing All rights reserved.

\begin{abstract}
A field trial was conducted for two consecutive winter seasons (2010/11 and 2011/12), at Demonstration Farm of Collage of Agricultural Studies, Sudan University of Science and Technology at Shambat, to study the effect of rhizobium, mycorrhiza inoculation and diammonium phosphate (DAP) on growth, nodulation and yield of soybean Glycine max (L.) Merrill introduced genotype (E01). The treatments consisted of control (without any fertilizer and inoculation), inoculation with Bradyrihzobium alone, and combinations of inoculation with Bradyrihzobium + mycorrhiza (VAM), Bradyrihzobium + mycorrhiza (VAM) $+100 \mathrm{~kg} / \mathrm{ha}$ diammonium phosphate (DAP), and Bradyrihzobium + vesicular arbuscular mycorrhiza (VAM) $+150 \mathrm{~kg}$ /ha diammonium phosphate (DAP). A completely randomized block design with four replicates was used. The results showed that the combination of Bradyrihzobium and mycorrhiza (VAM) produced significantly higher nodulation number/plant. Relative growth rate was significantly highest in combined of Bradyrihzobium, mycorrhiza (VAM) and $100 \mathrm{~kg} / \mathrm{ha}$ (DAP). Maximum grain yield was significantly obtained at par with combinations of Bradyrihzobium, mycorrhiza (VAM) and $150 \mathrm{~kg}$ /ha (DAP) and Bradyrihzobium, mycorrhiza (VAM) and $100 \mathrm{~kg} / \mathrm{ha}$ (DAP). In general the effect and interaction of rhizobium, mycorrhiza and diammonium phosphate rhizobium significantly increased nodulation number/plant, relative growth rate and yield of soybean over control. It can be concluded that genotype (E01) of irrigated soybean produced significantly highest growth and yield when combination of rhizobium with mycorrhiza and diammonium phosphate (DAP) was used during winter season under Khartoum conditions.
\end{abstract}

Keywords Effects, Inoculation, Rhizobium, Nodulation, Mycorrhiza, DAP, Soybean

\section{Introduction}

The soybean crop is one of the most important crops worldwide. Soybean grains are important as protein meal and vegetable oil Hartman et al [1]. Besides, it also contains various vitamins and minerals. It provides around $60 \%$ of the world. Supply of vegetable protein and $30 \%$ of the oil Fehr [2]. In the Sudan, soybean trials started as early as 1925 at Gezira Research Farm where a low yield was obtained. This low yield was attributed to lack of cultivars adaptable to the Sudan agro-ecological conditions. Lack of adaptable cultivar to the Sudan agro-ecological conditions has enormously contributed into the existing information gap on association of traits with seed yield Tony et al [3]. The country currently is importing vegetable oils for the local consumption, thus the introduction of new oil crop will cut these imports and help in the self sufficiency of such vital commodity.

Inoculation of legumes is widely practiced with the objective of increasing production of the legume. Rhizobium inoculation of soybean has been reported to increase growth and seed yield Jalaluddin [4], Kala et al. [5], Faisal [6]. Majid et al. [7] revealed that total number of nodules increased in inoculated over un inoculated control.

Mycorrhiza is widespread symbiotic associations that are commonly described as the result of co-evolution events between fungi and plants where both partners benefit from the reciprocal nutrient exchange Bonfante and Genre [8].Soybean nodulation, growth and yield were significantly increased by mycorrhizal inoculation Mahadi [9].

Diammonium phosphate (DAP) is the world's most widely used phosphorus fertilizer, containing $18 \% \mathrm{~N}$ and $46 \% \mathbf{P}_{2} \mathbf{O}_{5}$. Soybean is known to be highly nitrogen demanding crop, since the end product is very rich in protein. Biological $\mathbf{N}_{2}$ fixation and mineral soil or nitrogen fertilizer are the main source of meeting the nitrogen requirement of high-yielding soybean (Salvagiottiet et al. [10]. Phosphorus deficiency can limit nodulation, growth and yield of soybean and phosphorus fertilizer application can overcome the deficiency (Carsky, et al. [11], Kumaga and Ofori [12]. The objective of this experiment was to study the effects of rhizobium, mycorrhiza inoculation and DAP fertilization on growth and yield of soybean introduced genotype. 


\section{Materials and Methods}

A field experiment was carried out during two winters season of (2010/11 and 2011/12), at Demonstration Farm of Collage of Agricultural Studies, Sudan University of Science and Technology at Shambat., to evaluate the effect of inoculum, mycorrhizal, and diammonium phosphate fertilization on nodulation, growth and yield of soybean Glycine max (L.) Merrill. Shambat is Located 2335, longitude $15^{\circ} 31^{\prime}$, and altitude $288 \mathrm{~m}$ sea level, within the semi dry climate described by Adam [13] the soil of the site is loam clay it is characterized by a deep cracking, moderately alkaline clays, and low permeability, low nitrogen content and low $\mathrm{P}$ content ,PH (7.5-8) content (50-60\%) and high exchangeable sodium percentage (ESP), in subsoil. The land prepared by disc plough, harrowing, leveling and ridging. Spacing between ridges was $70 \mathrm{~cm}$, and then it was divided into plots $4 \times 3.5 \mathrm{~m} 2$ with four ridges, each 3.5 meters long. In all seasons, introduced genotype (E01) of soybean was used. The sowing dates were on 25 December in winter for each season. Inter-row spacing was $5 \mathrm{~cm}$ with one seed per hole on the top of the ridges and gaps were filled by replanting after germination. Irrigation was applied at an interval of 10 days. Weeding was done by hand whenever it was necessary to avoid weed competition. Seeds were inoculated by rhizobium ( Bradyrihzobium janponicum, strain USDA 122) and mycorrhiza (VAM) Glomus fasciculatum at sowing. Diammonium phosphate fertilization (DAP) content ( $18 \% \mathrm{~N}+46 \% \mathrm{P} 2 \mathrm{O} 5)$ was added after germination.

The treatments of this study were:

$\mathrm{C}=$ control (without inoculation or fertilizer)

$\mathrm{R}=$ Inoculation with rhizobium alone

$\mathrm{RM}=$ Inoculation with rhizobium + mycorrhiza

RMD1 = Inoculation with rhizobium + mycorrhiza +100 $\mathrm{kg} / \mathrm{ha}$ (DAP)

RMD2 = Inoculation with rhizobium + mycorrhiza +150 $\mathrm{kg} / \mathrm{ha}$ (DAP)

Five holes were selected randomly from the two inner ridges, leaving one meter at each end of the plot, then the mean plant was recorded. Relative growth rate (RGR) was determined by taking the above soil biomass of samples from area of $3.5 \mathrm{~m}^{2}$ twice; first after 28 days of germination $\left(\mathrm{DW}_{1}\right)$ and second after 10 days of first one $\left(\mathrm{DW}_{2}\right)$ and dried by oven immediately for 48 hours, then weighed and counted according to the formula $\mathrm{DW}_{2}-\mathrm{DW}_{1} /$ time $\mathrm{x}$ area. The roots of the second samples (after 38 days of germination) were used to count their nodules to determine the Nodulation number /plant. Grain yield /ha (kg) were calculated by dividing the plot yield by plot area and multiplied by $10.000 \mathrm{~m}^{2}$. Data generated was subjected to statistical analysis system "MSTAT-C software. One factor randomized complete block design (RCBD) was performed. Analysis of variance was carried out for treatments and means were tested and separated using Duncan Multiple Range Test (DMRT) referred to Steel et al. [14] at $P=0.05$.

\section{Results and Discussion}

\section{Nodulation number/plant}

In the present investigation as shown in the table (1) rhizobium (R) increased significantly nodulation number/ plant. Similar results were reported by Majid et al. [7] and Faisal [6]. Combination of rhizobium and mycorrhiza (RM) produced significantly the highest nodulation number/plant. This agreed with Taiwo et al. [15] and Mahadi [9] who reveal in general that dual inoculation with mycorrhiza and Bradyrhizobium significantly increased nodule number of soybean when compared with control. The interaction between rhizobium, mycorrhizal, 100 and $150 \mathrm{~kg} / \mathrm{ha}$ of diammonium phosphate increased number of nodules per plant over control. This positive result could be related to increase nutrient absorption by the rhizobium and mycorrhiza and nitrogen and phosphorus content in DAP fertilizer. This result agreed with those of Maurya and Rathi [16] Gan et al. [17], and Mrkovacki, [18] who reported in general that phosphorus, starter nitrogen, rhizobium and mycorrhiza increased nodulation number/plant of soybean. Nodulation failed in control treatment which could be related to absence of suitable rhizobium strain on fields. Similar result was reported by Papastylianou [19] and Yanni et al [27] who reported in general that soybean in non-inoculated plots with Rhizobium japonicum failed to nodulate.

Table 1. The effect of rhizobium, mycorrhiza and diammonium phosphate (DAP) on nodulation, relative growth rate and yield of soybean.

\begin{tabular}{|c|c|c|c|c|c|c|}
\hline \multirow[t]{2}{*}{ Treatments } & \multicolumn{2}{|c|}{ Nodulation NO./plant } & \multicolumn{2}{|c|}{ RGR } & \multicolumn{2}{|c|}{ Yield kg/ha } \\
\hline & $(2010 / 11)$ & $(2011 / 12)$ & $(2010 / 11)$ & $(2011 / 12)$ & $(2010 / 11)$ & $(2011 / 12)$ \\
\hline Control (C) & $0.0^{\mathrm{e}}$ & $0.8^{\mathrm{e}}$ & $0.3^{\mathrm{d}}$ & $0.4^{\mathrm{d}}$ & $576.9^{d}$ & $236.4^{d}$ \\
\hline Rhizobium (R) & $24.5^{\mathrm{c}}$ & $17.3^{\mathrm{c}}$ & $0.6^{c}$ & $0.6^{\mathrm{c}}$ & $760.2^{c}$ & $274.1^{\mathrm{c}}$ \\
\hline $\begin{array}{c}\text { Rhizobium }+ \text { VAM mycorrhiza } \\
(\mathrm{RM})\end{array}$ & $40.0^{\mathrm{a}}$ & $32 .^{a}$ & $1.3^{\mathrm{b}}$ & $0.8^{\mathrm{b}}$ & $804.1^{\mathrm{b}}$ & $304.8^{\mathrm{b}}$ \\
\hline $\begin{array}{c}\text { Rhizobium + VAM mycorrhiza + } \\
100 \mathrm{~kg} / \mathrm{ha}(\mathrm{RMD} 1)\end{array}$ & $28.3^{\mathrm{b}}$ & $23.5^{\mathrm{b}}$ & $1.6^{\mathrm{a}}$ & $1.5^{\mathrm{a}}$ & $941.2^{\mathrm{a}}$ & $537.5^{\mathrm{a}}$ \\
\hline $\begin{array}{c}\text { Rhizobium + VAM mycorrhiza + } \\
150 \mathrm{~kg} / \mathrm{ha}(\mathrm{RMD} 2)\end{array}$ & $16 .^{\mathrm{d}}$ & $11.3^{\mathrm{d}}$ & $1.4^{\mathrm{b}}$ & $0.9^{\mathrm{b}}$ & $956.6^{\mathrm{a}}$ & $542.9^{a}$ \\
\hline S.E $=$ & \pm 0.3 & \pm 0.7 & \pm 0.3 & \pm 0.1 & \pm 79.0 & \pm 11.7 \\
\hline C.V\% & 3.1 & 8.7 & 23.2 & 17.6 & 19.9 & 15.6 \\
\hline
\end{tabular}

Any two means with same letter are not significantly different at 5\% level, using Duncan Multiple Range Test. 


\section{Relative growth rate $\left(\mathrm{g} / \mathrm{m}^{2} / \mathrm{day}\right)$}

As shown in the table (1), it is clear that rhizobium (R) increased significantly relative growth rate over control (C). In this connection, Ali [20] found similar result on chickpea. The combination of rhizobium and mycorrhiza (RM) increased significantly relative growth rate. Jose et al. [21] reported that mycorrhiza increased relative growth rate of palm which agreed with this result. Combination of rhizobium + mycorrhiza $+150 \mathrm{~kg} / \mathrm{ha}$ DAP (RMD2) registered significantly higher relative growth rate (RGR) as compared to control. The best relative growth rate was recorded in the combination of rhizobium + mycorrhiza + $100 \mathrm{~kg} / \mathrm{ha}$ DAP (RMD1). This may be related to DAP mineral contents and the nutrient absorption by the rhizobium and mycorrhiza. Similar results by Goswami and Soni [22], Abdel-Fattah [23], Mahamood et al. [24] and Ali [20] agreed with this observation. They reported in general that the interaction between chemical and bio-fertilizers significantly increased relative growth rate of soybean.

\section{Grain yield $\mathrm{kg} / \mathrm{ha}$}

It is evident from the data presented in table (1), that rhizobium (R) increased significantly grain yield, over control (C). Ibrahim et al. [25] also observed that at shambat region inoculation significantly improved yield, which agreed with the study. The interaction between rhizobium and mycorrhiza (RM) increased significantly grain yield as compared to control. Same result was found by Young et al. [26] who reported that mixed inoculation with rhizobium and mycorrhiza increased yields of soybean. The grain yield/ha obtained from combinations of rhizobium, mycorrhiza and $150 \mathrm{~kg} / \mathrm{ha}$ DAP (RMD2) was found to be at par with that of combination of rhizobium + mycorrhiza $+100 \mathrm{~kg} / \mathrm{ha}$ DAP (RMD1) and they produced significantly the highest grain yield /ha. This might be due to the combine effect of DAP, which contains phosphorus and nitrogen as well as enhancement of phosphorus and nitrogen availability to plants by rhizobium and mycorrhiza. Some results reported by Yanni et al. [27], Malik et al. [28], Majumdar [29], Rezende [30], Kazi [31], and Mehmet [30] referred in general that mycorrhiza, rhizobium, phosphorus and nitrogen increased grain yield of soybean. The second season (winter 2011/12) was warmer than the first (winter 2010/11) this was reflected in the low grain yield.

\section{Conclusions}

The above mentioned results indicated that genotype (E01) of soybean produced significantly highest nodulation number per plant, relative growth rate and grain yield when combination of rhizobium with mycorrhiza and diammonium phosphate (DAP) was used during winter season under Khartoum conditions.

\section{Acknowledgements}

The authors are grateful to Dr. Awad Galal, National Center for Research, Sudan and Mr. Esmail El-Munsor, Department of Agronomy, College of Agricultural studies, Sudan University of Science and Technology, for their valuable help.

\section{REFERENCES}

[1] Hartman GL, West ED, Herman TK.( 2011). Crops that feed the World 2. Soybean-worldwide production, use, and constraints caused by pathogens and pests. Food Sec 3:5-17

[2] Fehr, W.R., Robbelin, G., Downey, R.K., Ashri, A.Mc. ( 1989). Soybean, Oil crops of the world. McGraw-Hill publishing Company, London.

[3] Tony. N, Muhammad. A, and Silvestro. M (2013) Soybean (Glycine max L) genotype and environment interaction effect on yield and other related traits American Journal of Experimental Agriculture 3(4): 977-987.

[4] Jalaluddin, M. (2005). Effect of inoculation with vamfungi and bradyrhizobium on growth and yield of soybean in Sindh. Pak. J. Bot. 37: 169-173

[5] Kala, T. C.; Christi, R.M., and Bai, N. R. (2011). Effect of rhizobium inoculation on growth and yield of horsegram (Dolichos biflorus L.). Plant Archives, 11(1), pp. 97-99

[6] Faisal E. A (1986). Interactive effect of nitrogen fertilization and rhizobium inoculation on nodulation and yield of soybean (Glycine max L. Merrill) Canadian Journal of Microbiology, 1986, 32(1): 22-27, 10.1139/m86-005

[7] Majid M. T., M. Kaleem A.i . R., Abdul Khaliq and M. H. Kazmi( 2009). Effect of Rhizobium inoculation and NP fertilization on growth, yield and nodulation of soybean (Glycine max) African Journal of Biotechnology Vol. 8 (22), pp. 6191-6200

[8] Bonfante, P. and A. Genre.(2008). Plants and arbuscular mycorrhizal fungi: an evolutionary-developmental perspective. Trends Plant Sci. 13:492-498.

[9] Mahadi.A.A. (2004). Influence of mycorrhizal inoculation form of phosphate fertilization and watering regime on nodulation and yield of soybean. 45-46 U. of K. J. Agric. Sci. 12/3. 2004.

[10] Salvagiottiet F, Cassman KG, Specht JE, Walters DT, Wiss A, Dobermann A (2008). nitrogen uptake, fixation and response to fertilizer $\mathrm{N}$ in soybean: a review. Field Crop Res., 108: 1-13.

[11] Carsky, R. J., Singh, B. B., \& Oyewole, R. (2001). Contribution of early-season cowpea to late season maize in the savanna zone of West Africa. Biol. Agric. Hort., 18, 303-315.

[12] Kumaga, F. K., \& Ofori, K. (2004). Response of soybean to Bradyrhizobia inoculation and phosphorus application. Int. J. Agric. and Bio. 6(2): 324-327.

[13] Adam. H.S (2002). The agricultural climate second edition. 
Gezria university press. Wad- Madani, Sudan. In Arabic. Pp 119.

[14] Steel RGD and Torrie JH (1997). Principles and procedures of statistics: A biometrical approach, Second Edition. McGraw Hill, New York.

[15] Taiwo-LB; Adegbite-AA (2001) Effect of arbuscular mycorrhizal and bradyrhizobium inoculation on growth, N2 fixation and yield of promiscuously nodulating soybean (Glycine max). Moor-Journal-of-Agricultural-Research. 2001, 2: 2, 110-118; 33 ref

[16] Maurya, B.M., Rathi, K.S., (2000) Growth and development of soybean as influenced by intercropping with pigeon pea and phosphorus level. Gujarat Agricultural University Research Journal 26(1), 1-5.

[17] Gan-YinBo; Stulen-I; Posthumus-F; Keulen-H-van; Kuiper-PJC; Gan-YB; van-Keulen-H (2002) Effects of N management on growth, N2 fixation and yield of soybean. : Nutrient-Cycling-in-Agroecosystems. 2002, 62: 2, 163-174; 47 ref

[18] Mrkovacki N, Marinkovic J, Rcimovic R (2008). Effect of N Fertilizer Application on Growth and Yield of Inoculated Soybean. Not. Bot. Hort. Agrobot. Cluj. 36: 48-51

[19] Papastylianou (1986) Effect of nitrogen fertilization and inoculation with Rhizobia on nodulation and nitrogen and grain yield of soybean. :Miscellaneous-Reports,-Agricultural-Research-Ins titute,-Cyprus. 1986, No. 26, 6 pp.; 13 ref

[20] Ali Namvar,Raouf Seyed Sharifi,Teymur Khandan (2011) Growth analysis and yield of chickpea (Cicer arietinum L.) in relation to organic and inorganic nitrogen fertilization. EKOLOGIJA. 2011. Vol. 57. No. 3. P. 97-108

[21] Jose Ramos-Zapata, Roger Orellana, Patricia Guadarrama Salvador Medina-Peralta (2009) Contribution of Mycorrhizae to Early Growth and Phosphorus Uptake by a Neotropical Palm. Journal of Plant Nutrition. Volume 32p. 855-866

[22] Goswami-SR; Soni-SN (2001) Response of soybean to graded levels of phosphorus and different methods of placement in terms of growth, grain production efficiency and economics of cultivation. Advances-in-Plant-Sciences. 2001, 14: 2, 583-586; 9 ref.

[23] Abdel-Fattah- GM (2002). Measurement of the viability of arbuscular- mycorrhizal fungi colonized of root using three different strains and its reaction to growth and metabolic activities of soybean plant. Agrochemical 46:5, 177-189; 45.
[24] Mahamood. J, Y. A. Abayomi and M. O. Aduloju (2009) Comparative growth and grain yield responses of soybean genotypes to phosphorous fertilizer application. African Journal of Biotechnology Vol. 8 (6), pp. 1030-1036,

[25] Ibrahim KA, Elsheikh EAE, Naim AMEI, Mohamed EA (2011). Effect of Bradyrhizobium Inoculation on Yield and Yield's Components of Soybean (Glycine max (L.) grown in Sudan. Australian Journal of Basic and Applied Sciences. 5(7): 793-799.

[26] Young-CC; Juang-TC; Chao-CC (1989) Effects of Rhizobium and vesicular-arbuscular mycorrhiza inoculations on nodulation, symbiotic nitrogen fixation and soybean yield in subtropical-tropical fields. Biology-and-Fertility-of-Soils. 1988, 6: 2, 165-169; 4 tab.; 26 ref

[27] Yanni-YG; El-Beheiry-MM; Hoda-FM; Beheiry-MM-El (1987) Nodulation, vegetative growth, infestation with the spider mite, Tetranychus cucurbitacearum (Sayed) and seed yield of N-fertilized soybean plants in the Nile Delta. MIRCEN-Journal-of-Applied-Microbiology-and-Biotechnol ogy. 1987, 3: 3, 297-306; 20 ref

[28] Malik M. A., Cheema M. A., Khan H. Z. (2006) Growth and yield response of soybean (Glycine max L.) to seed inoculation and varying phosphorus levels. Journal of Agricultural Research. Vol. 44(1): 47-53.

[29] Majumdar-B;Venkatesh-MS;Lal-B; Kailash-Kumar; Kumar-K (2001) Response of soybean (Glycine max) to phosphorus and sulphar in acid alfisol of Meghalaya. Indian Journal- of agronomy.46:3,500-505

[30] Rezende-PM-de; Andrade-MJB-de; Resende-GM; Botrel-EP; de-Rezende-PM; de-Andrade-MJB (2001) Maximization of soybean (Glycine max (L.) Merrill) exploration. Effects of cutting time and $\mathrm{P}$ fertilizer upon regrowth grain hay yield. Ciencia-e-Agrotecnologia. 2001, 25: 2, 311-320; 29 ref

[31] Kazi-BR; Oad-FC; Jamro-GH; Jamali-LA; Kumar-L (2002) Yield of soybean as affected by water stress and phosphorus levels. Pakistan-Journal-of-Applied-Sciences. 2002, 2: 5, $560-562 ; 14$ ref

[32] Kazi-BR; Oad-FC; Jamro-GH; Jamali-LA; Kumar-L (2002) Yield of soybean as affected by water stress and phosphorus levels. Pakistan-Journal-of-Applied-Sciences. 2002, 2: 5, 560-562; 14 ref

[33] Mehmet OZ (2008) Nitrogen rate and plant population effects on yield and yield components in soybean. African Journal of Biotechnology Vol. 7 (24), pp. 4464-4470, 17 